Article

\title{
Identification of a Biosynthetic Gene Cluster Responsible for the Production of a New Pyrrolopyrimidine Natural Product-Huimycin
}

\author{
Hui Shuai ${ }^{1}$, Maksym Myronovskyi ${ }^{1}$, Suvd Nadmid ${ }^{1,2}$ and Andriy Luzhetskyy ${ }^{1,3, *}$ \\ 1 Pharmazeutische Biotechnologie, Universität des Saarlandes, 66123 Saarbrücken, Germany; \\ hui.shuai@uni-saarland.de (H.S.); maksym.myronovskyi@uni-saarland.de (M.M.); suvdn@yahoo.com (S.N.) \\ 2 School of Pharmacy, Mongolian National University of Medical Sciences, S. Zorig Street, \\ 14210 Ulaanbaatar, Mongolia \\ 3 Helmholtz-Institut für Pharmazeutische Forschung Saarland, 66123 Saarbrücken, Germany \\ * Correspondence: a.luzhetskyy@mx.uni-saarland.de; Tel.: +49-0681-70223
}

Received: 21 June 2020; Accepted: 16 July 2020; Published: 18 July 2020

\begin{abstract}
Pyrrolopyrimidines are an important class of natural products with a broad spectrum of biological activities, including antibacterial, antifungal, antiviral, anticancer or anti-inflammatory. Here, we present the identification of a biosynthetic gene cluster from the rare actinomycete strain Kutzneria albida DSM 43870, which leads to the production of huimycin, a new member of the pyrrolopyrimidine family of compounds. The huimycin gene cluster was successfully expressed in the heterologous host strain Streptomyces albus Del14. The compound was purified, and its structure was elucidated by means of nuclear magnetic resonance spectroscopy. The minimal huimycin gene cluster was identified through sequence analysis and a series of gene deletion experiments. A model for huimycin biosynthesis is also proposed in this paper.
\end{abstract}

Keywords: kutzneria; nucleoside; pyrrolopyrimidines; secondary metabolites; heterologous expression

\section{Introduction}

Pyrrolopyrimidines are a class of natural products characterized by the presence of a 7-deazapurine moiety in their structures [1]. This class of compounds is widely spread among three domains of life: archaea, bacteria, and eukarya [1]. The study of pyrrolopyrimidines began in 1956 with the discovery of an anti-Candida compound, toyocamycin, in the culture broth of Streptomyces toyocaensis [2]. Soon after the discovery of toyocamycin, other secreted 7-deazapurine compounds, tubercidin and sangivamycin, were isolated from the culture filtrates of Streptomyces tubercidicus and Streptomyces rimosus $[3,4]$. To date, more than 30 different 7-deazapurines have been isolated from various biological sources, including bacteria, cyanobacteria, red algae, marine sponges, and tunicates [1]. In addition to secreted pyrrolopyrimidines, which act as natural products, pyrrolopyrimidines can also be found as modified bases in tRNA. Queuosine is one of the most studied modified nucleosides that contains a 7-deazapurine moiety [5]. It is present in the wobble position of aspartyl, asparaginyl, histidyl and tyrosyl tRNA, where it likely modifies base pairing characteristics of tRNA and enhances translational efficiency [6-8]. Distributed ubiquitously among prokaryotes and eukaryotes, queuosine cannot be found in archaebacteria. In archaeal species, archeosine, a noncanonical 7-deazapurine nucleoside, is incorporated into tRNA [9].

Secreted pyrrolopyrimidines often possess antibacterial, antifungal, anticancer, antiviral or anti-inflammatory activities [1,10-12]. Their structural similarity to purine bases allows 7-deazapurines to interfere with various cellular processes involving nucleotides and nucleosides [1]. For instance, toyocamycin and tubercidin have been shown to be substrates of mammalian adenosine 
kinase [13]. In the phosphorylated form, toyocamycin is recognized by mammalian DNA and RNA polymerases and can become incorporated into DNA and RNA [14]. Although pyrrolopyrimidines are not substrates for amino acid aminoacylation, toyocamycin and sangivamycin inhibit this process [15]. When incorporated into the acceptor stem of tRNA, pyrrolopyrimidine inhibits tRNA aminoacylation [15]. Sangivamycin has recently been demonstrated to inhibit protein kinases [16,17]. A broad range of biological activities characteristic of pyrrolopyrimidines makes them promising potential drug leads for the pharmaceutical industry. Recent U.S. food and drug administration (FDA) approval of ribociclib and baricitinib, which both contain a 7-deazapurine moiety, for the treatment of breast cancer and rheumatoid arthritis further emphasizes the pharmaceutical importance of the pyrrolopyrimidine class of compounds [18,19].

In this study, we report the identification and heterologous expression of a biosynthetic gene cluster of Kutzneria albida DSM 43870 that encodes a new member of the pyrrolopyrimidine family of natural products, huimycin. The compound was isolated, and its structure was elucidated using extensive 2D nuclear magnetic resonance spectroscopy (NMR). Through a series of DNA deletion experiments, the minimal cluster required for huimycin biosynthesis was determined. Based on the cluster analysis, we also propose the biosynthetic route that produces huimycin.

\section{Materials and Methods}

\subsection{Strains and $B A C S$}

All of the strains used in this study are listed in Table S1. The BACs are listed in Table S2. Escherichia coli strains were cultured in LB medium [20]. For sporulation and conjugation, Streptomyces strains were cultivated on soya flour mannitol agar (MS agar) [21] and in liquid tryptic soy broth (TSB; Sigma-Aldrich, St. Louis, MO, USA). DNPM medium was used for secondary metabolite production liquid [22]. The antibiotics ampicillin, kanamycin, apramycin, hygromycin and nalidixic acid were supplemented when required.

\subsection{DNA Manipulation}

Isolation of DNA and all subsequent manipulations were performed according to standard protocols [20]. BAC extraction from the genomic library of $K$. albida was performed using the BACMAX ${ }^{\mathrm{TM}}$ DNA purification kit (Lucigen, Middleton, WI, USA). Restriction endonucleases were used according to manufacturer's recommendations (New England Biolabs, Ipswich, MA, USA). All of the primers used in this study are listed in Table S3.

To determine the minimal huimycin biosynthetic cluster a series of BACs with the deletions of single and multiple genes was constructed. In the BACs 2I16_LS and 2I16_RS large DNA regions upstream and downstream of the putative huimycin cluster were deleted. In the BACs 2I16_4069, 2I16_4074, 2I16_4075, and 2I16_4076, the genes KALB_4069, KALB_4074, KALB_4075, and KALB_4076 were inactivated. In the BAC 2I16_LS $20 \mathrm{~kb}$ DNA fragment upstream of the huiA gene was deleted. For this purpose, the hygromycin gene was amplified from the pACS-hyg plasmid with the LS-F/LS-R pair of primers. The obtained PCR fragment was used for the Red-ET modification of the BAC 2I16 [23]. The constructed BAC 2I16 was checked by restriction mapping (Figure S1) and PCR with the LS_chF/LS_chR pair of primers with subsequent sequencing of the obtained PCR product.

The BACs 2I16_RS, 2I16_4069, 2I16_4074, 2I16_4075 and 2I16_4076 were constructed in a similar manner. Here, ampicillin resistance marker was used for recombineering purposes instead of hygromycin marker. The marker was amplified from the pUC19 plasmid with the pairs of primers RS_F/RS_R, 4069_F/4069_R, 4074_F/4074_R, 4075_F/4075_R, and 4076_F/4076_R. The obtained PCR products were utilized for the construction of the abovementioned BACs using Red-ET modification. The construction of the BACs was confirmed using restriction mapping (Figure S1), PCR with the pairs of primers RS_chF/RS_chR, 4069_chF/4069_chR, 4074_chF/4074_chR, 4075_chF/4075_chR, 4076_chF/4076_chR, and sequencing. 


\subsection{Metabolite Extraction and Analysis}

Streptomyces albus strains containing 2I16 BAC and its derivatives were grown in $15 \mathrm{~mL}$ of TSB medium for $24 \mathrm{~h}$. One $\mathrm{mL}$ of the seed culture was used for inoculation of $100 \mathrm{~mL}$ of DNPM medium. The cultures were cultivated for seven days at $28^{\circ} \mathrm{C}$. Huimycin was extracted with the equal amount of butanol from the culture supernatant, evaporated, and dissolved in methanol.

For mass determination a Bruker Amazon Speed and a Thermo LTQ Orbitrap XL mass spectrometer were used. Both machines were coupled to UPLC Thermo Dionex Ultimate3000 RS. Analytes were separated on a Waters ACQUITY BEH C18 Column $(1.7 \mu \mathrm{m}, 2.1 \mathrm{~mm} \times 100 \mathrm{~mm})$ with water $+0.1 \%$ formic acid and acetonitrile $+0.1 \%$ formic acid as the mobile phase.

\subsection{Huimycin Isolation and NMR Data Acquisition}

Streptomyces albus $2 \mathrm{I} 16$ was cultivated into $20 \mathrm{~L}$ of DNPM medium at $28{ }^{\circ} \mathrm{C}$ for seven days. The mycelial part was separated by centrifugation. The supernatant was extracted once with the equal amount of butanol. The solvent was evaporated under vacuum in a rotary evaporator. The huimycin was purified using size-exclusion and reverse phase chromatography. Size-exclusion chromatography was performed using Sephadex LH-20 (GE Healthcare, USA) and methanol as a solvent. The HPLC separation was performed on semipreparative HPLC (Dionex UltiMate 3000, Thermo Fisher Scientific, USA) equipped with a C18 column (Synergi $10 \mu \mathrm{m}, 250 \times 10 \mathrm{~mm}$; Phenomenex, Aschaffenburg, Germany). Water $+0.1 \%$ formic acid and acetonitrile $+0.1 \%$ formic acid were used as the mobile phase.

NMR spectra were recorded in meod 4 at $500 \mathrm{MHz}$ on a Bruker Avance 500 spectrometer (Bruker, BioSpin $\mathrm{GmbH}$, Rheinstetten, Germany) equipped with a $5 \mathrm{~mm}$ TXI cryoprobe. HSQC, $\mathrm{HMBC},{ }^{1} \mathrm{H}-{ }^{1} \mathrm{H}$ COSY, and 2D TOCSY experiments were acquired using standard pulse program. CNST13 of HMBC were set as 2,3JC-H $=2,8$ and $10 \mathrm{~Hz}$.

\subsection{Genome Mining and Bioinformatics Analysis}

The K. albida genome was screened for secondary metabolite biosynthetic gene clusters using the antiSMASH online tool [24]. Geneious R9 (Biomatters Ltd.) software package was used for DNA sequence analysis.

\section{Results and Discussion}

\subsection{Identification of the Huimycin Gene Cluster Through Its Heterologous Expression in Streptomyces albus Del14}

Recently, we reported the complete genome sequence of Kutzneria albida DSM 43870 (GenBank accession number NZ_CP007155), which is a representative of a rarely observed genus in the Pseudonocardiaceae family [25]. Forty-six putative clusters encoding secondary metabolites were identified in the genome of this strain [25]. To enable analysis of these metabolites, a genomic library of $K$. albida was constructed using an integrative BAC vector. In the course of systematic activation of cryptic secondary metabolite clusters from K. albida, a cluster annotated by the antiSMASH genome mining software as "nucleoside biosynthetic cluster" was expressed in the heterologous host strain S. albus Del14. For this purpose, a BAC 2I16 vector containing the cluster was isolated from the constructed genomic library and transferred into the chassis strain S. albus Del14 by conjugation. The obtained exconjugant strain S. albus $2 \mathrm{I} 16$ and the corresponding control strain without the BAC S. albus Del14 were fermented in the production medium DNPM. The culture filtrate of the strains was extracted with butanol, and the extracts were analyzed by liquid chromatography-mass spectrometry (LC-MS). This analysis revealed a new peak in the extract of S. albus $2 \mathrm{I} 16$ as a result of the cluster expression (Figure 1). Subsequent analysis of the extract using high resolution LC-MS revealed that the identified peak corresponded to a compound with an $[\mathrm{M}+\mathrm{H}]+$ of $393.15 \mathrm{~m} / \mathrm{z}$ (Figure 1). The extract of the control strain S. albus Del14 did not contain the identified ion. A search in a natural product 
database for the identified high-resolution mass did not generate any matches, implying that the identified compound might be new.
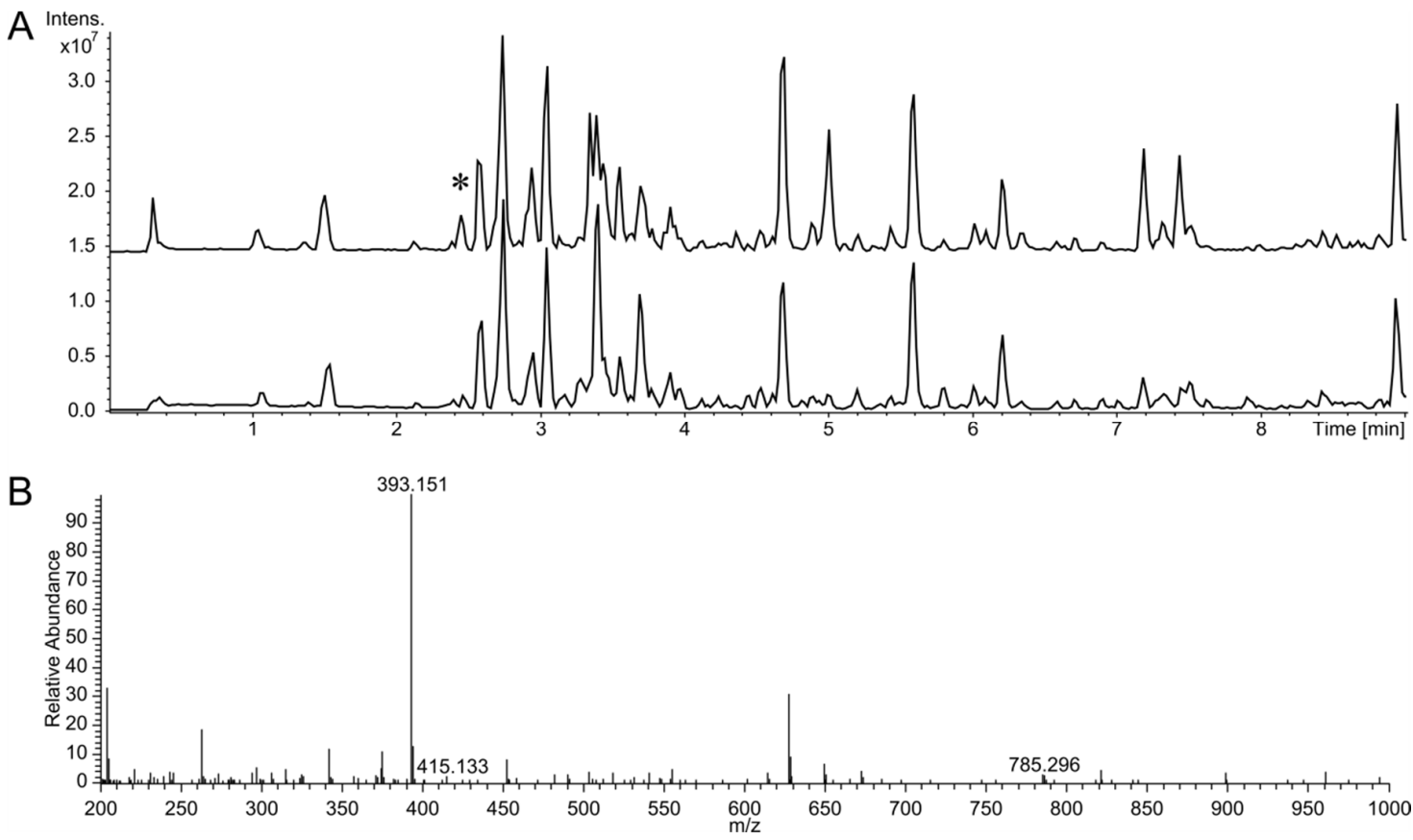

Figure 1. Liquid chromatography-mass spectrometry detection of huimycin. (A) Base peak chromatograms of crude extracts of S. albus 2I16 harboring the huimycin gene cluster (upper chromatogram) and of the control strain S. albus Del14 (lower chromatogramm). The new peak found in the S. albus 2 I16 extract is indicated with an asterix. (B) High resolution mass spectrum of the new peak corresponding to huimycin. The molecular ion peaks at $\mathrm{m} / \mathrm{z} 393.151,415.133$ and 785.296 correspond to huimycin $[\mathrm{M}+\mathrm{H}]+$, its sodium adduct $[\mathrm{M}+\mathrm{Na}]+$ and its dimer $[2 \mathrm{M}+\mathrm{H}]^{+}$.

\subsection{Isolation and Structure Elucidation of the Huimycin}

To obtain structural information about the potentially new compound obtained from the heterologous expression of the nucleoside gene cluster, we set out to purify it. For this purpose, the S. albus 2I16 strain with the expressed nucleoside gene cluster was inoculated into $20 \mathrm{~L}$ of DNPM medium, and the culture broth was extracted with butanol. The compound was separated from contaminants in the extract using size-exclusion and reverse-phase chromatography. A total of $8.2 \mathrm{mg}$ of the compound was isolated during the purification process and was used for subsequent structure elucidation purposes (Figures S2-S9).

The combination of the ${ }^{1} \mathrm{H}$ NMR spectrum with the HSQC data indicated an isolated aromatic signal, one anomeric methine, one methoxy signal together with three oxygenated methines and one methylene signal as well as a methyl group. The TOCSY and COSY spectra suggested the presence of a sugar moiety, which was determined to be 1-amino-2-deoxy-glucose by means of analyzing HMBC cross peaks. $\mathrm{HMBC}$ correlations from $\mathrm{H}-2^{\prime}$ and $\mathrm{H}-9^{\prime}$ to $\mathrm{C}-8^{\prime}$ further revealed the substitution of an acetate on the amino group of the sugar (Table 1). The large coupling constant observed for the anomeric proton of the glucose moiety at $5.28(\mathrm{~d}, \mathrm{~J}=9.6 \mathrm{~Hz})$ suggested its $\beta$-orientation. Further ROESY correlations were observed between $\mathrm{H} 1^{\prime} / \mathrm{H}^{\prime} / \mathrm{H}^{\prime}$ as well as $\mathrm{H} 2^{\prime} / \mathrm{H} 4^{\prime}$ of the glucose moiety.

The constitution of the aglycone core was determined to be a purine bearing substitutions at C-2, C-6 and C-7. Several HMBC experiments with different long-range coupling constants (CNST13) were used to link the substitutions to the correct positions. The HMBC spectrum acquired with CNST13 $=2 \mathrm{~Hz}$ showed a more intense cross peak from the H-8 to a carbon at $\delta 160.3$ than what was observed in the $\mathrm{HMBC}$ with $10 \mathrm{~Hz}$ data, suggesting that the carbon at $\delta 160.3(\mathrm{C}-2)$ is the furthest carbon from $\mathrm{H}-8$ and shows a five bond correlation. Furthermore, according to $\mathrm{HMBC}$, the alpha proton of 
the sugar moiety showed correlation with C-2, indicating its linkage. The methoxy group was found to be linked on C-6 because of the HMBC correlation (in CNST13 = $2 \mathrm{~Hz}$ data) of methyl protons to C-5 (at $\delta 98.7 \mathrm{ppm}$ ), showing a four-bond heteronuclear correlation. Due to the biosynthetic similarity of this molecule to toyocamycin and their NMR data similarity, the cyano-group was deduced to be attached to C-7. This was supported by the HMBC correlation from H-8 to carbon at $\delta 116.3(\mathrm{C}-10)$ and the chemical shift of C-7 at $\delta 84.5 \mathrm{ppm}$.

Table 1. Nuclear magnetic resonance spectroscopy data of huimycin.

\begin{tabular}{cccc}
\hline Position & $\delta_{\mathbf{C}}{ }^{\mathbf{a}}$ & $\delta_{\mathbf{H}}$ mult. $(\mathbf{J}, \mathbf{H z})^{\mathbf{b}}$ & HMBC $^{\mathbf{c}}$ \\
\hline 2 & 160.3 & & \\
4 & 155.4 & & \\
5 & 98.7 & & \\
6 & 164.5 & & $2 \mathrm{2}, 4,5,6^{\mathrm{e}}, 7,10$ \\
7 & 84.5 & $7.60, \mathrm{~s}$ & $5^{\mathrm{e}}, 6$ \\
8 & 131.0 & & $2,2^{\prime}, 3^{\prime}, 5^{\prime}$ \\
10 & 116.3 & $4.05, \mathrm{~s}$ & $1^{\prime}, 3^{\prime}, 8^{\prime}$ \\
11 & 54.2 & $5.28, \mathrm{~d} 9.6$ & $2^{\prime}, 4^{\prime}$ \\
$1^{\prime}$ & 83.6 & $3.87^{\mathrm{d}}$ & $5^{\prime}, 6^{\prime}$ \\
$2^{\prime}$ & 56.1 & $3.55, \mathrm{~m}$ & $4^{\prime}$ \\
$3^{\prime}$ & 76.3 & $3.38^{\mathrm{d}}$ & \\
$4^{\prime}$ & 71.9 & $3.39^{\mathrm{d}}$ & $8^{\prime}$ \\
$5^{\prime}$ & 79.2 & $3.69, \mathrm{~m}$ & \\
$6^{\prime} \mathrm{a}$ & 62.6 & $3.85^{\mathrm{d}}$ & \\
$6^{\prime} \mathrm{b}$ & & & \\
$8^{\prime}$ & 174.5 & $1.96, \mathrm{~s}$ & \\
$9^{\prime}$ & 22.7 & & \\
\hline
\end{tabular}

a Acquired at $125 \mathrm{MHz}$, referenced to solvent signal meod4 at $\delta 49.15 \mathrm{ppm} .{ }^{\mathrm{b}}$ Acquired at $500 \mathrm{MHz}$, referenced to solvent signal meod4 at $\delta 3.31 \mathrm{ppm}$. ${ }^{\mathrm{c}}$ Proton showing HMBC correlation to indicated carbons. ${ }^{\mathrm{d}}$ Overlapped signals. ${ }^{\mathrm{e}}$ Observed in HMBC with CNST13 $=2 \mathrm{~Hz}$.

Finally, the planar structure was deduced, as shown in Figure 2, which is in concordance with the HR-ESI-MS data (measured 393.1509, calculated 393.1517, $\Delta$ ppm 2.0). The isolated compound was named huimycin and was identified as a novel natural compound. Structurally, huimycin is closely related to dapiramicins $\mathrm{A}$ and $\mathrm{B}$, differing from the latter only in the sugar moiety attached to the aglycone (Figure 2) [26,27].
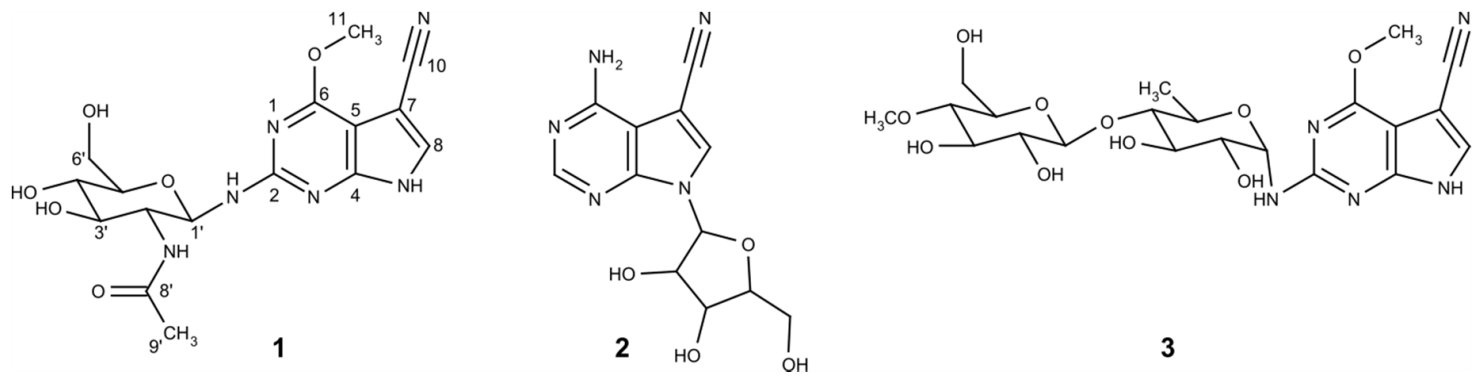

Figure 2. The structures of (1) huimycin, (2) toyocamycin, and (3) dapiramicin A.

\subsection{Determination of the Minimal Huimycin Gene Cluster}

The presence of a 7-deazapurine moiety, typical of a pyrrolopyrimidine class of nucleoside antibiotics [1], in the structure of the isolated huimycin indicates the participation of the expressed nucleoside cluster in its production. The huimycin gene cluster was expressed in the heterologous host strain as a part of the large 95-kb chromosomal fragment in BAC 2I16. To determine the minimal set of genes required for huimycin biosynthesis, a sequence analysis and a series of gene deletion experiments were performed. 
The sequence analysis of the DNA fragment cloned in BAC 2I16 leading to nucleoside production revealed the presence of seven open reading frames, huiA - huiG (locus tags KALB_4067 - KALB_4073), which are highly likely to be involved in huimycin biosynthesis (Figure 3, Table 2). Five of these genes shared homology at the protein level with the genes within the biosynthetic cluster of toyocamycin-the parent compound of the pyrrolopyrimidine class of antibiotics (Figure 2, Table 2) [28]. The huiA gene, encoding a putative transcriptional regulator, shares homology with the regulatory gene toy $A$ [28]. The genes huiB, huiD, huiE and huiF encode putative 7-cyano-7-deazaguanine synthase, 6-carboxytetrahydropterin synthase, 7-carboxy-7-deazaguanine synthase and GTP cyclohydrolase I, and they share homology with the toyocamycin biosynthetic genes toy $M, \operatorname{toy} B, \operatorname{toy} C$ and toy $D$, respectively (Table 2) [28]. The structural similarities between huimycin and toyocamycin also imply similar biosynthetic routes leading to the production of antibiotics. The genes huiC and huiG do not have counterparts in the toyocamycin gene cluster; they encode putative SAM-dependent methyltransferase and glycosyltransferase, respectively (Table 2). The genes huiC and huiG are likely responsible for the structural differences between huimycin and toyocamycin.

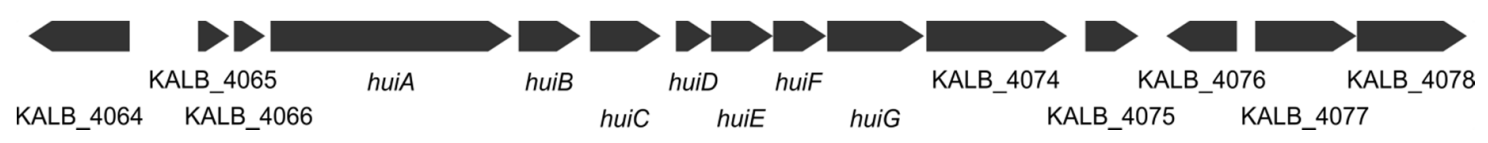

Figure 3. The chromosomal fragment of K. albida containing the huimycin biosynthetic gene cluster.

Table 2. Proposed functions of the genes in the DNA fragment containing huimycin gene.

\begin{tabular}{|c|c|c|c|}
\hline Gene & Proposed Function & $\begin{array}{c}\text { Homolog in Toy } \\
\text { Pathway }\end{array}$ & Identities/Positives \\
\hline KALB_4064 & Enhanced intracellular survival protein & & \\
\hline KALB_4065 & Hypothetical protein & & \\
\hline KALB_4066 & Hypothetical protein & & \\
\hline huiA; KALB_4067 & Pathway-specific regulator & toy $A$ & $33 \% / 46 \%$ \\
\hline huiB; KALB_4068 & 7-cyano-7-deazaguanine synthase & toyM & $72 \% / 82 \%$ \\
\hline huiC; KALB_4069 & SAM-dependent methyltransferase & & \\
\hline huiD; KALB_4070 & 6-carboxytetrahydropterin synthase & toy $B$ & $65 \% / 76 \%$ \\
\hline huiE; KALB_4071 & 7-carboxy-7-deazaguanine synthase & toyC & $50 \% / 55 \%$ \\
\hline huiF; KALB_4072 & GTP cyclohydrolase I & toy $D$ & $66 \% / 75 \%$ \\
\hline huiG; KALB_4073 & Glycosyltransferase & & \\
\hline KALB_4074 & Carbamoyltransferase & & \\
\hline KALB_4075 & Pyridoxamine $5^{\prime}$-phosphate oxidase & & \\
\hline KALB_4076 & SAM-dependent methyltransferase & & \\
\hline KALB_4077 & Glycosyltransferases & & \\
\hline KALB_4078 & Glycosyltransferases & & \\
\hline
\end{tabular}

The gene huiA encodes a transcriptional regulator and was assumed to constitute the $5^{\prime}$ outer border of the huimycin cluster (Figure 3). The counterpart of the gene huiA within the toyocamycin biosynthetic pathway, toy $A$, also constitutes the first gene of the cluster [28]. The deletion of the toy $A$ gene completely abolishes toyocamycin production [29]. The first three genes in the region upstream of the huiA gene, KALB_4064, KALB_4065, and KALB_4066 (Figure 3), encode an enhanced intracellular survival protein and two hypothetical proteins, respectively. No function in nucleoside biosynthesis could be assigned to these three genes. This further strengthens the assumption that the huiA gene constitutes the $5^{\prime}$ boundary of the cluster. To corroborate this assumption empirically, the $20 \mathrm{~kb}$ DNA fragment upstream of the huiA gene was deleted within the 2I16 BAC through RedET recombineering. The obtained construct, 2I16_LS, resulted in huimycin production when it was transferred into an S. albus strain. This clearly indicated that the genes in the upstream region of the huiA are not required for huimycin biosynthesis. Thus, it is likely that the huiA gene is at the $5^{\prime}$ end of the huimycin gene cluster. 
Prediction of the $3^{\prime}$ boundary of the huimycin cluster was not obvious from the gene annotation. The last gene showing homology to toyocamycin biosynthetic genes is huiF (Table 2). This gene is followed by the gene huiG, which encodes a glycosyltransferase that might participate in nucleoside biosynthesis. The genes KALB_4074,KALB_4075,KALB_4076, KALB_4077, and KALB_4078 in the downstream region of the huiG encode a putative carbamoyltransferase, pyridoxamine $5^{\prime}$-phosphate oxidase family protein, SAM-dependent methyltransferase, and two glycosyltransferases, respectively. As is evident in the huimycin structure (Figure 2), glycosyltransferase and methyltransferase activities are required to produce huimycin. The required methyltransferase may be encoded either by huiC or by KALB_4076. It is also not obvious which of the three glycosyltransferase genes, huiG, KALB_4077 or KALB_4078, participates in huimycin biosynthesis. To clarify this, the $36 \mathrm{~kb}$ DNA fragment downstream of the KALB_4076 gene was deleted in the 2I16 BAC. The obtained BAC 2I16_RS led to huimycin production when introduced into $S$. albus. This clearly indicates that the genes in the downstream region of KALB_4076, including the two glycosyltransferase genes KALB_4077 and KALB_4078, do not participate in huimycin biosynthesis. The possible participation of the genes KALB_4074,KALB_4075, and KALB_4076 in huimycin biosynthesis was assessed by their inactivation in the 2I16 BAC. The obtained BACs (2I16_4074, 2I16_4075 and 2I16_4076) contained the deletions of the genes KALB_4074,KALB_4075 and KALB_4076, respectively, and they resulted in huimycin production when introduced in S. albus. This shows that none of the inactivated genes is essential for huimycin production. Thus, it is likely that the huiG gene is at the $3^{\prime}$ end of the huimycin gene cluster.

Deletion of the genes located outside the huiA - huiG fragment have been shown not to affect the huimycin production in the heterologous strain $S$. albus. These genes are considered not to participate in huimycin biosynthesis, however a possibility exists that some of the deleted genes are crosscomplemented by one or several host genes. To demonstrate the importance of the huiA-huiG fragment for nucleoside production, the huiC gene, encoding the methyltransferase, was deleted from the 2I16 BAC. The deletion of the huiC gene completely abolished the production of the huimycin, showing its involvement in the production of this nucleoside.

\subsection{Biosynthesis of Huimycin}

Seven genes, huiA-huiG, have been shown to be sufficient for huimycin production. The huiA gene encodes a putative transcriptional regulator and is likely to be involved in the regulation of expression of the huimycin biosynthetic gene cluster. The homolog of huiA, the toyA gene, encodes a pathway-specific regulator of the toyocamycin gene cluster [28]. The six genes, huiB-huiG, encode structural enzymes that catalyze huimycin biosynthetic steps. The products of the genes huiB, huiD, $h u i E$, and huiF display significant sequence similarity with the products of the toyocamycin biosynthetic genes toy $M$, toy $B, \operatorname{toy} C$, and toyD, respectively. The genes huiC and huiG have no homologs in the toyocamycin cluster and encode a putative methyltransferase and glycosyltransferase, respectively. The considerable sequence similarity between huimycin and toyocamycin gene clusters implies the similarities in the biosynthetic routes leading to the production of the compounds.

Similar to toyocamycin, GTP is regarded as a main precursor for huimycin production $[1,28]$. The first reaction in huimycin biosynthesis is the conversion of GTP into 7,8-dihydroneopterin triphosphate (H2NTP) (Figure 4). This reaction is catalyzed by the product of the gene huiF, which encodes a putative GTP cyclohydrolase I. The product of the huiF gene shares $66 \%$ identity with the product of the toy $D$ gene, which also catalyzes the first step of the toyocamycin biosynthesis $[1,28]$. The second step in the pathway is catalyzed by 6-carboxytetrahydropterin synthase encoded by huiD, which converts H2NTP into 6-carboxy-5,6,7,8-tetrahydropterin (CPH4) (Figure 4). The product of the huiD gene shares $65 \%$ identity with the product of $t o y B$, which is responsible for the similar reaction in the toyocamycin biosynthesis $[1,28]$. The third biosynthetic step is catalyzed by the product of the toyC homolog, huiE, which encodes 7-carboxy-7-deazaguanine synthase. This enzyme converts CPH4 into 7-carboxy-7-deazaguanine (CDG) [1,28]. The products of toyC and huiE share $50 \%$ identity. The last step common for both huimycin and toyocamycin biosynthesis is the conversion of the 
CDG into 7-cyano-7-deazaguanine (PreQ0) through the action of 7-cyano-7-deazaguanine synthase (Figure 4). This enzyme is encoded by the toyM homolog, huiB. The protein products of these genes share $72 \%$ identity. We propose that the last two enzymatic steps required for the conversion of PreQ0 into huimycin are the methylation of 7-cyano-7-deazaguanine and the attachment of the N-acetylglucosamine moiety (Figure 4). The methylation reaction is likely to be catalyzed by the product of the gene huiC, which encodes a SAM-dependent methyltransferase. The attachment of the $\mathrm{N}$-acetylglucosamine to the 2-amino-6-methoxy-7-cyano-7-deazapurine is catalyzed by the glycosyltransferase encoded by the last gene in the huimycin gene cluster - huiG. The order in which the last two reactions take place in the huimycin biosynthesis is not known. The isolation of dapiramicin B aglycone (2-amino-4-methoxy-5-cyanopyrrolo[2,3-d]pyrimidine) from the culture of Streptomyces sp. MK63-43F2 implies that that methyltransfer reaction precedes glycosylation [30]. Huimycin is thus far the only known member of the pyrrolopyrimidine class of compounds with an $\mathrm{N}$-acetylglucosamine moiety in its structure. Additionally, the position of the N-glycosidic bond distinguishes huimycin from most of the 7-deazapurine nucleosides. Only in the structures of dapiramicin A and B, sugar moieties are also attached to the amino group at the second position of the 7-deazapurine chromophore (Figure 2) [26,27]. Furthermore, dapiramicin A and B share the same chromophore as huimycin. Since the dapiramicin biosynthetic gene cluster has not yet been discovered, it is not possible to study whether the structural similarities between huimycin and the dapiramicins are also reflected on the DNA sequence level. The identified huimycin biosynthetic genes can be used to screen sequenced genome databases to identify gene clusters potentially encoding pyrrolopyrimidines distinct from toyocamycin.

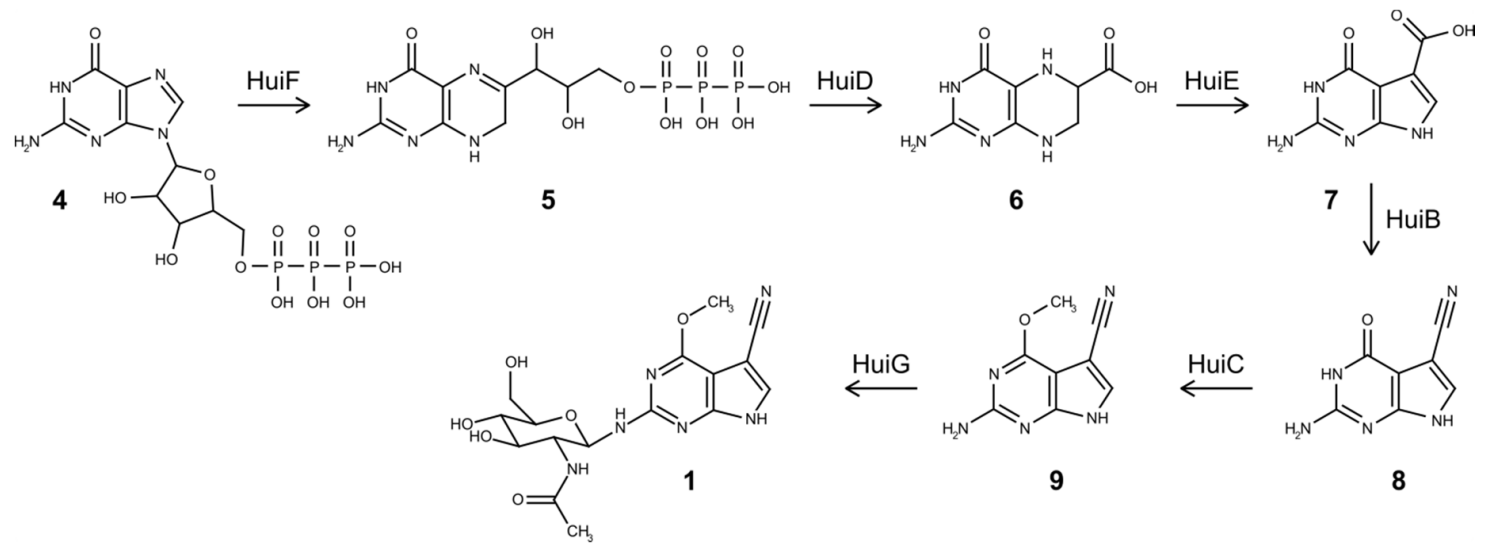

Figure 4. Proposed biosynthetic pathway of huimycin. (4) GTP, (5) 7,8-dihydroneopterin triphosphate, (6) 6-carboxy-5,6,7,8-tetrahydropterin, (7) 7-carboxy-7-deazaguanine, (8) 7-cyano-7-deazaguanine, (9) 2-amino-6-methoxy-7-cyano-7-deazapurine, and (1) huimycin.

\section{Conclusions}

In this paper, we reported the identification and successful heterologous expression of the gene cluster responsible for the production of huimycin, a new member of the pyrrolopyrimidine family of nucleoside natural products. Huimycin features that are unique for nucleosides include an N-acetylglucosamine moiety attached to the 2-amino-6-methoxy-7-cyano-7-deazapurine core. The minimal set of huimycin biosynthetic genes was identified through a series of gene deletion experiments. The expression of the huimycin gene cluster in S. albus reported here is the first example of successful heterologous expression of a secondary metabolite pathway from the rare actinomycetal genus Kutzneria. 
Supplementary Materials: The following are available online at http://www.mdpi.com/2218-273X/10/7/1074/s1, Figure S1: Restriction mapping of the BAC 2I16 and its derivatives with gene deletions, Figure S2: ${ }^{1} \mathrm{H}$ NMR (500 MHz, MeOD4) spectrum of huimycin 1, Figure S3: HSQC (500 MHz, MeOD4) spectrum of huimycin 1, Figure S4: HMBC (500 MHz, MeOD4) spectrum (CNST13 = $2 \mathrm{~Hz})$ of huimycin 1, Figure S5: HMBC $(500 \mathrm{MHz}, \mathrm{MeOD} 4)$ spectrum $(\mathrm{CNST} 13=6 \mathrm{~Hz})$ of huimycin 1, Figure S6: HMBC (500 MHz, MeOD4) spectrum $(\mathrm{CNST} 13=10 \mathrm{~Hz})$ of huimycin 1, Figure S7: ${ }^{1} \mathrm{H}-{ }^{1} \mathrm{H}$ COSY $(500 \mathrm{MHz}, \mathrm{MeOD} 4)$ spectrum of huimycin 1, Figure S8: TOSCY (500 MHz, MeOD4) spectrum of huimycin 1, Figure S9: ROESY (500 MHz, MeOD4) spectrum of huimycin 1, Table S1: Bacterial strains used in this work, Table S2: Plasmids and BACs used in this work, Table S3: Primers used in this study.

Author Contributions: Design of the experiments, H.S., M.M., and A.L.; performing of the experiments, H.S. performed the experiments; performing and evaluation of the NMR analysis, S.N. performed and evaluated the NMR analysis; analysis of the data and writing of the manuscript, H.S., M.M., and A.L.; revision of the manuscript, all authors reviewed the manuscript. All authors have read and agreed to the published version of the manuscript.

Funding: This research received no external funding.

Acknowledgments: H.S. would like to acknowledge financial support provided by the China Scholarship Council (CSC).

Conflicts of Interest: The authors declare no conflict of interest.

\section{References}

1. McCarty, R.M.; Bandarian, V. Biosynthesis of pyrrolopyrimidines. Bioorg. Med. Chem. 2012, 43, 15-25. [CrossRef] [PubMed]

2. Nishimura, H.; Katagiri, K.; Sato, K.; Mayama, M.; Shimaoka, N. Toyocamycin, a new anti-candida antibiotics. J. Antibiot. 1956, 9, 60-62. [PubMed]

3. Anzai, K.; Nakamura, G.; Suzuki, S. A new antibiotic, tubercidin. J. Antibiot. 1957, 10, 201-204. [PubMed]

4. Rao, K.V. Structure of sangivamycin. J. Med. Chem. 1968, 11, 939-941. [CrossRef]

5. Vinayak, M.; Pathak, C. Queuosine modification of tRNA: Its divergent role in cellular machinery. Biosci. Rep. 2009, 30, 135-148. [CrossRef]

6. Harada, F.; Nishimura, S. Possible anticodon sequences of tRNA His, tRNA Asm, and tRNA Asp from Escherichia coli B. Universal presence of nucleoside $\mathrm{Q}$ in the first postion of the anticondons of these transfer ribonucleic acids. Biochemistry 1972, 11, 301-308. [CrossRef]

7. Meier, F.; Suter, B.; Grosjean, H.; Keith, G.; Kubli, E. Queuosine modification of the wobble base in tRNAHis influences "In Vivo" decoding properties. EMBO J. 1985, 4, 823-827. [CrossRef]

8. Urbonavicius, J.; Qian, Q.; Durand, J.M.; Hagervall, T.G.; Björk, G.R. Improvement of reading frame maintenance is a common function for several tRNA modifications. EMBO J. 2001, 20, 4863-4873. [CrossRef]

9. Kilpatrick, M.W.; Walker, R.T. The nucleotide sequence of the tRNAMMet from the archaebacterium Thermoplasma acidophilum. Nucleic Acids Res. 1981, 9, 4387-4390. [CrossRef]

10. Pathania, S.; Rawal, R.K. Pyrrolopyrimidines: An update on recent advancements in their medicinal attributes. Eur. J. Med. Chem. 2018, 157, 503-526. [CrossRef]

11. Saneyoshi, M.; Tokuzen, R.; Fukuoka, F. Antitumor Activities and Structural Relationship of Tubercidine, Toyocamycin, and Their Derivatives. GANN Jpn. J. Cancer Res. 1965, 56, 219-222. [CrossRef]

12. Acs, G.; Reich, E.; Mori, M. Biological and biochemical properties of the analogue antibiotic tubercidin. Proc. Natl. Acad. Sci. USA 1964, 52, 493-501. [CrossRef] [PubMed]

13. Lindberg, B.; Klenow, H.; Hansen, K. Some properties of partially purified mammalian adenosine kinase. J. Biol. Chem. 1967, 242, 350-356. [CrossRef]

14. Suhadolnik, R.J.; Uematsu, T.; Uematsu, H. Toyocamycin: Phosphorylation and incorporation into RNA and DNA and the biochemical properties of the triphosphate. Biochim. Biophys. Acta 1967, 149, 41-49. [CrossRef]

15. Uretsky, S.C.; Acs, G.; Reich, E.; Mori, M.; Altwerger, L. Pyrrolopyrimidine nucleotides and protein synthesis. J. Biol. Chem. 1968, 243, 306-312. [PubMed]

16. Loomis, C.R.; Bell, R.M. Sangivamycin, a nucleoside analogue, is a potent inhibitor of protein kinase C. J. Biol. Chem. 1988, 263, 1682-1692. [PubMed]

17. Osada, H.; Sonoda, T.; Tsunoda, K.; Isono, K. A new biological role of sangivamycin; inhibition of protein kinases. J. Antibiot. 1989, 42, 102-106. [CrossRef] 
18. Roskoski, R. Properties of FDA-approved small molecule protein kinase inhibitors. Pharmacol. Res. 2019, 144, 19-50. [CrossRef]

19. Mogul, A.; Corsi, K.; McAuliffe, L. Baricitinib: The Second FDA-Approved JAK Inhibitor for the Treatment of Rheumatoid Arthritis. Ann. Pharmacother. 2019, 53, 947-953. [CrossRef]

20. Green, M.R.; Sambrook, J. Molecular Cloning: A Laboratory Manual, 4th ed.; Cold Spring Harbor Laboratory Press: Plainview, NY, USA, 2012.

21. Kieser, T.; Bibb, M.J.; Buttner, M.J.; Chater, K.F.; Hopwood, D.A. Practical Streptomyces Genetics; John Innes Foundation: Norwich, UK, 2000.

22. Rodríguez Estévez, M.; Myronovskyi, M.; Gummerlich, N.; Nadmid, S.; Luzhetskyy, A. Heterologous Expression of the Nybomycin Gene Cluster from the Marine Strain Streptomyces albus subsp. chlorinus NRRL B-24108. Mar. Drugs 2018, 16, 435. [CrossRef]

23. Muyrers, J.P.P.; Zhang, Y.; Benes, V.; Testa, G.; Rientjes, J.M.J.; Stewart, A.F. ET recombination: DNA engineering using homologous recombination in E. coli. Methods Mol. Biol. 2004, 256, 107-121. [CrossRef] [PubMed]

24. Blin, K.; Shaw, S.; Steinke, K.; Villebro, R.; Ziemert, N.; Lee, S.Y.; Medema, M.H.; Weber, T. antiSMASH 5.0: Updates to the secondary metabolite genome mining pipeline. Nucleic Acids Res. 2019, 47, W81-W87. [CrossRef] [PubMed]

25. Rebets, Y.; Tokovenko, B.; Lushchyk, I.; Rückert, C.; Zaburannyi, N.; Bechthold, A.; Kalinowski, J.; Luzhetskyy, A. Complete genome sequence of producer of the glycopeptide antibiotic Aculeximycin Kutzneria albida DSM 43870T, a representative of minor genus of Pseudonocardiaceae. BMC Genom. 2014, 15, 885. [CrossRef] [PubMed]

26. Shomura, T.; Nishizawa, N.; Iwata, M.; Yoshida, J.; Ito, M.; Amano, S.; Koyama, M.; Kojima, M.; Inouye, S. Studies on a new nucleoside antibiotic, dapiramicin. I. Producing organism, assay method and fermentation. J. Antibiot. 1983, 36, 1300-1304. [CrossRef]

27. Nishizawa, N.; Kondo, Y.; Koyama, M.; Omoto, S.; Iwata, M.; Tsuruoka, T.; Inouye, S. Studies on a new nucleoside antibiotic, dapiramicin. II. Isolation, physico-chemical and biological characterization. J. Antibiot. 1984, 37, 1-5. [CrossRef]

28. McCarty, R.; Bandarian, V. Rosetta stone for deciphering deazapurine biosynthesis: Pathway for pyrrolopyrimidine nucleosides toyocamycin and sangivamycin. Chem. Biol. 2008, 15, 790-798. [CrossRef]

29. Xu, J.; Song, Z.; Xu, X.; Ma, Z.; Bechthold, A.; Yu, X. ToyA, a positive pathway-specific regulator for toyocamycin biosynthesis in Streptomyces diastatochromogenes 1628. Appl. Microbiol. Biotechnol. 2019, 103, 7071-7084. [CrossRef]

30. Iijima, M.; Kubota, Y.; Sawa, R.; Kubota, Y.; Hatano, M.; Igarashi, M.; Kawada, M.; Momose, I.; Takekawa, M.; Shibasaki, M. A guanine derivative as a new MEK inhibitor produced by Streptomyces sp. MK63-43F2. J. Antibiot. 2017. [CrossRef]

(C) 2020 by the authors. Licensee MDPI, Basel, Switzerland. This article is an open access article distributed under the terms and conditions of the Creative Commons Attribution (CC BY) license (http://creativecommons.org/licenses/by/4.0/). 